\title{
The Adoption of Cloud Computing Among Private Banks Employees in Libya
}

\author{
Salem Asseed Alatresh ${ }^{\mathbf{1}}$, Faisal Muftah Ahmed ${ }^{2}$ \\ ${ }^{1,2}$ Department of Computer Science, Bani Waleed University
}

\begin{tabular}{ll}
\hline ARTICLE INFO & ABSTRACT \\
\hline $\begin{array}{l}\text { Published Online } \\
\text { 16 November 2021 }\end{array}$ & $\begin{array}{l}\text { The adoption of cloud computing (CC) by individuals and banking institutions garnered little } \\
\text { attention. The goal of this study is to examine the factors that influence the adoption of CC by Libyan } \\
\text { private bank personnel. According to the findings, employees' behavioral intention (BI) to adopt CC } \\
\text { is significantly influenced by individual elements (performance expectation (PE), effort expectation } \\
\text { (EE), social influence (SI), attitude (AT), and IT knowledge (ITK), among others. User happiness } \\
\text { with cloud computing has been proposed to moderate the impact of individual elements on BI (SaaS). }\end{array}$ \\
$\begin{array}{l}\text { A total of 309 Libyan bank workers were randomly selected to participate in the study. Analyses of } \\
\text { Corresponding Author: }\end{array}$ \\
$\begin{array}{l}\text { Moment Structures were used in the study (AMOS). The findings of the study show that the BI's use } \\
\text { of CC is influenced by a variety of personal circumstances. It was partially mediated by satisfaction } \\
\text { Alatresh }\end{array}$ & $\begin{array}{l}\text { in BI's decision to employ CC. Employees at private banks will be more likely to use CC if they focus } \\
\text { on their own needs. }\end{array}$
\end{tabular}

KEYWORDS: Cloud computing, banking, private banks, user satisfaction, UTAUT

\section{INTRODUCTION}

The adoption of cloud computing (CC) by banks has not received much attention from researchers(Asadi et al., 2016). The majority of the studies regarding the $\mathrm{CC}$ adoptions by banks are industrial reports of $\mathrm{CC}$ providers or consultancy companies and it is noticed that the banking industry was a late adopter of the CC technology (Boulton, 2016; IBM, 2016; Mckinsey, 2016). Several advantages can be gained by the financial institution when using CC technology. These advantages include cost minimization, on-demand usage, business continuity, as well as business agility, and green IT (Boulton, 2016). Nevertheless, one of the most important steps before moving to CC technology is to assess the acceptance of employees for the new technology (Capgemini, 2011).

However, CC projects have a significant failure probability when it comes to financial enterprises despite extensive research and advancement (Elzamly et al., 2016). The banking sector is undergoing a major transformation. The client, not the bank, currently holds the reins of power. The new plans of action are being driven by the needs of the customers. Their use of technology is driving business transformation. To meet the needs of their customers, banks must develop new strategies, activities, and technology. Banks' incentive for distributed computing has a direct impact on their entire operations. An alternative paradigm for communicating imaginative client encounters an enticing combined effort is provided by cloud innovation. In recent years, cloud computing has become more secure and widely used (IBM, 2013).

While most researches regarding the adoption of CC covers countries with highly developed IT infrastructure, CC is used also in less IT-mature countries (El-Gazzar, 2014; Guner and Sneiders, 2014). In Libya, the banking industry is suffering due to the ongoing conflict in the era after the collapse of the previous regime. Many international reports by the World Bank, the United Nations (UN) referred to the severity of the challenges that face the Libyan economy. Nevertheless, several private banks have introduced the services of online banking in Libya since 2009 but the acceptance of these services are still limited (Mohamed, 2013).

In Libya, online banking technology is used at a very low rate (Eljayash, 2015). It is time for Libya's banking sector to undergo a major overhaul, as it has been widely criticized for its poor and inefficient services (Mohamed, 2013). It's been shown in previous research that the use of technology, such as electronic government (E-government), electronic commerce (e-commerce), and electronic business (e-business), can increase productivity (Elkaseh et al., 2015). Even in Libya and other developing nations, there is limited research on the use of CC in general. In addition, the banking industry's adoption of CC is restricted in both developed and less developed countries (Boulton, 2016; McKinsey, 2016; IBM, 2016). 
Recent studies showed that the perspective of customers toward the adoption of CC was investigated, however; a lack existed in the perspective of employees toward adoption of cloud (Asadi et al., 2016).

Using the unified theory of acceptance and use of technology (UTAUT) paradigm, previous research has shown that alternative technology acceptance models, such as the Technology Acceptance Model (TAM), are insufficient (Venkatesh et al., 2003). A variety of fields have benefited from the model's versatility. However, the model's application in CC remains restricted (Cao et al., 2013). The use of technology in banks enhances the efficiency of the institution and provides a competitive edge (Alaaraj et al., 2015; Alaarj et al., 2016). When it comes to CC adoption in Libyan private banks, this study is looking at the impact of individual aspects. Individual components such as UTAUT, PE, EE, SI, AT, and ITK were integrated into the study based on the literature, which included AT and ITK. Next, the literature review, methods, findings and discussion are covered in the following part.

\section{LITERATURE REVIEW}

This section discusses the CC and the development of the hypotheses.

\subsection{Cloud computing and Banking}

$\mathrm{CC}$ is a new technology in information technology that have been recently developed to enable users and business to access software, hardware, and application on-demand basis from anywhere (Low et al., 2011; Shawish and Salama, 2014). Therefore, the cloud resulted in shifting the applications to service platforms rather than to be installed on the personal computers of users. The American National Institute of Standards and Technology (NIST) has a widely accepted definition of CC (NIST). Network access to a shared pool of configurable computing resources that may be swiftly supplied and released with minimal management effort or service provider engagement" is NIST's definition of the paradigm (Mell and Grance, 2011).

Scientists have come to an agreement that there are three basic layers of cloud computing: the software layer, the platform layer and the infrastructure layer (Lian, 2015; Low et al., 2011). CC's deployment was also emphasized as a key factor by researchers. Cloud computing is one of the most essential considerations for the adoption of CC. Private, public, communal, and hybrid cloud deployments can be classified into four categories: (Mell\&Grance, 2011; Lian, 2015). Each type has its advantages and disadvantages (Zhang and Chen, 2010). Consider both technological and organizational aspects while deciding on a CC deployment model (Zhang and Chen, 2010).

The usage of CC by banks can make an agile and adaptable banking condition that can react rapidly to new business necessities. This is additionally taken a toll sparing, as banking institutions are required to pay on the usage-based for useful utilization and the services that they utilize(Alaaraj et al., 2017; Alaarj et al., 2017; Patani et al., 2014). Albeit numerous extensive banks are sure about the acknowledgment of cloud innovation, others are more watchful and anticipate the administrative difficulties to be addressed before hopping onto the temporary fad. With serve and tight monetary-related confinements, develop fiscal programming commercial centre and quickly evolving controls, there is the requirement for banks to seek innovative answers for meeting business prerequisites in today server competitive environment(Alaaraj et al., 2017; Apostu et al., 2012).

\subsection{Conceptual Model and Hypotheses Development}

This study uses mainly the UTAUT. The study focuses on the effect of individual factors on the adoption of CC in the banking industry in Libya. Several researchers operationalized human or individual factors into dimensions. For example, Lian et al. (2014) investigated the human factor effect on the adoption of CC e-government and included factors such as EE, PE, and SI. Liu et al (2008) deployed individual factors to test the adoption of new technology. In this study, individual factors are divided into PE, EE, SI, AT, and ITK. The choice of these factors and grouping them under individual factor construct is supported by previous studies. PE, EE, and SI are individual factors according to Venkatesh et al. (2003). ITK is related to the knowledge of an individual regarding the use of a specific technology (Al-Masri and Ahmad, 2017), AT toward the technology is an individual-oriented trait (Davis, 1989). User satisfaction with the technology is a core variable that can enhance the explanation of the relationship between individual factors and technological factors on one hand and the BI on the other hand. Thus, this variable is proposed as a mediator between individual factors and technological factors, and the BI uses the CC. Figure 1 presents the proposed framework of this study.

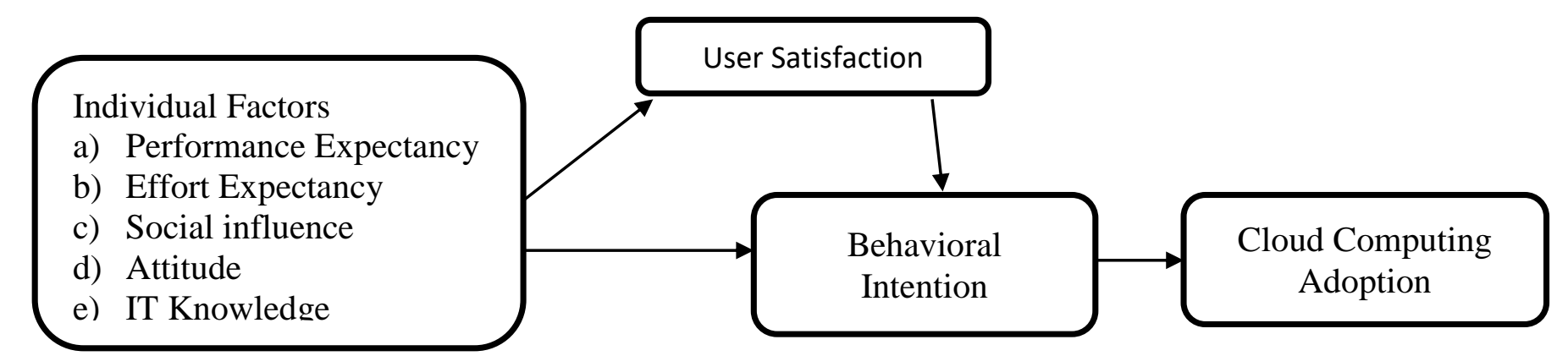

Figure 1: Proposed Conceptual Model 


\subsubsection{Individual Factors}

Individual factors are defined in this study as "the factors that concern the individual and lead them to adopt the CC technology. These factors include PE, EE, SI, AT, and ITK. Lian et al. (2014) investigated CC adoption and found that human factors have a significant effect on the adoption of CC. Liu et al. (2011) also found that the individual factors affect significantly the adoption of EDI technology. In this study, individual factors are expected to affect the behavioural intention to use the $\mathrm{CC}$ in the banking industry in Libya. Thus, it is hypothesized:

\section{H1: Individual factors affect positively the BI}

\subsubsection{Performance Expectancy}

PE is described as "the extent to which an individual believes that adopting the technology will aid him or her to improve the work performance" (Venkatesh et al., 2012). Peer endorsement (PE) has been scientifically proven to influence user adoption of new technology. Adoption of CC was found to be influenced by a user's perception of the technology's expected benefits (Park and Kim, 2014). Cao et al. (2013) discovered that PE had a significant impact on the adoption of CC. As part of this research, it is hypothesized that:

\section{H2: PE has a significant effect on BI.}

\subsubsection{Effort Expectancy}

EE is described as "the degree of ease with which the technology can be utilized" (Venkatesh, et al., 2012). It has been found that Lian (2015) used the UTAUT model to examine whether CC customers will use E-invoices. According to the research, EE influences the use of CC services. Two studies have indicated that EE had a significant impact on the intention to use CC in China and Saudi Arabia, respectively, Cao et al (2013) and Bellaaj et al (2015) It is hypothesized in this study:

\section{H3: EE has a significant effect on BI}

\subsubsection{Social Influence}

SI is defined as "the degree to which an individual perceives that it is important others believe he or she should use the new technology" (Venkatesh, et.al. 2012). The UTATU model emphasized that SI plays an important role in IT adoption (Venkatesh et al., 2003). SI affects user adoption of CC (Lian, 2015). Park and Ryoo, (2013)found that SI positively affects users' intention to use CC. $\mathrm{Wu}(2011 \mathrm{~b})$ found that SI affects the adoption of SaaS. Similarly, the study of Wu, (2011a) empirically found that SI is one of the key predictors of the adoption of CC. Therefore, it is hypothesized:

\section{H4: SI has a significant effect on BI}

\subsubsection{Attitude}

For example, "an individual's favorable or negative evaluation of a certain activity" can be defined as "AT" (Albakri et al., 2014). The AT toward technology has been hypothesized and evaluated in previous studies. Using empirical evidence, Albakri et al. (2014) concluded that AT towards technology is one of the most crucial markers for the adoption of M-banking. Adopters' perceptions and ATs were examined about the adoption of CC. For the technology to be adopted, Wu (2011) found that AT toward the CC is needed. The acceptance of CC is influenced by the use of AT, according to Arpaci(2016). A study by Arpaci, Kilicer, and Bardakci (2015) indicated that AT has a considerable impact on the likelihood that a business will use cloud computing. In this regard, it is proposed that

\section{H5: AT toward technology has a significant effect on the BI}

\subsubsection{IT knowledge}

It refers to "the ability of the workforce to use new technologies" as defined by ITK (Lian et al., 2014). This innovation would have a greater favorable AT if employees had IT skills. As a result, if the employees have the required abilities to embrace CC, then they are more likely to feel secure in participating in this process (Lian et al. 2014). We projected that ITK will have an impact on the use and performance of CC, according to Picoto and colleagues (2014). ITK was revealed to be a major element in Iran's adoption of E-government using a similar technique (Dehkordi et al., 2011). It is hypothesized in this study:

\section{H6: ITK has a significant effect on BI}

\subsubsection{Behavioral Intention and Cloud Adoption}

BI is defined as "a person's perceived likelihood or subjective probability that he or she will engage in a given behavior" (Venkatesh et al., 2003). Most previous models in technology acceptance proposed that BI affects the user behavior of new technology (Davis, 1989). Bellaaj, Zekri and Albugami (2015)found that BI affects the use behavioral of educational technology systems. Arpaci, Kilicer and Bardakci (2015) found that BI affects CC usage in educational institutions. In this study, it is hypothesized that: 


\section{H7: BI has a significant effect on CC adoption.}

\subsubsection{Mediating Role of User Satisfaction}

Affective state (SA) is described as "the emotional response of a user to the full experience of CC" (Burda and Teuteberg, 2014). The impact of SA on the intention to use mobile cloud services was examined by Park and Kim (2014) and found to be considerable (Park and Kim, 2014). According to Pilevari, Toloei, and Sanaei (2013), if people are satisfied with a piece of technology, they are more likely to adopt and employ it. Satisfaction with the technology has a favorable impact on trust and the utility of the cloud, according to Burda and Teuteberg (2014). SA was proposed by DeLone and McLean (2003) as a mediator between information quality, system quality, and service quality, and the intention to use technology. - DeLone Service and system quality have an impact on the ease of use and utility, according to Wixom and Todd (2005). SA's ability to moderate the interaction between factors has long been demonstrated in marketing research (Chiu and Francesco, 2003; Rezvani et al., 2016; Spagnoli and Caetano, 2012). However, this relationship should be studied in the realm of CC adoption. In this regard, it is proposed that:

\section{H8: SA mediates the effect of individual factors on the BI}

\section{RESEARCH METHODOLOGY}

The population of this study includes all the private banks in Libya, which have experience of online banking and intended or have a CC technology existed in their banks. According to the central bank in Libya, the country has 18 public and private banks. The total number of banks that use online banking is 11 out of which nine are private banks. These nine banks are the target population of this study. The number of employees at these banks is estimated to be 26000 employees including the branches of the banks. Out of the 26,000, 6000 employees are involved in IT-related tasks. These 6000 are the target population of this study. This study uses the random sampling selection method to determine the sample size from the population. Accordingly, the sample size of this study is 361 and it is sufficient for the use of AMOS (Lowry and Gaskin, 2014).

\subsection{Instrument of the Study}

This study is using a questionnaire as a tool for data collection. The questions are measured using a five-point Likert scale. PE (5 items), EE (5 items), SI (5 items), and BI (5 items) were adopted from Lian (2015). AT (4 items) was adopted from Davis (1989). ITK (5 items) was adopted from Dehkordiet al. (2011) and user behavior (8 items) was adopted from Gupta et al. (2013) and Davis et al. (1989). Two experts validated the instrument of this study and pilot testing was conducted to ensure that the measurements are reliable. Cronbach's Alpha for all the measurements was greater than 0.70 indicating the reliability of the measurements.

\subsection{Data Collection}

After confirming the instrument validity and reliability, the field data collection took place between February and July 2017. A total of 397 online questionnaires were mailed out to respondents. Follow-up procedures were applied to increase the response rate. Emails and other social media tools were used to post the questionnaire and request to be answered by IT staff in the banks. A total of 324 responses were collected representing a response rate of $69 \%$. These responses are sufficient for the use of AMOS (Alaaraj et al., 2018).

\subsection{Data Examination}

A series of analyses was conducted to refine and prepare the data. Missing value analysis showed that there is no missing value. Outliers analysis indicated the existence of 15 univariate and multivariate outliers. This has resulted in 309 complete and usable responses. The data is normally distributed and the value of skewness and kurtosis are within the recommended range of less than the absolute value of two and there is no multicollinearity issue because the tolerance is greater than 0.10 and the variance inflation factor (VIF) is greater than 10 .

\section{DATA ANALYSIS}

The data were analysed using SPSS and AMOS version 22.0. This section presents the profile of respondents and the result of hypotheses testing.

\subsection{Demographic Information}

Table 1 shows the demographic information of the respondents. A total of 309 respondents has participated in this study. Respondents are males (76.7\%) while females accounted for $23.3 \%$. A total of $37.9 \%$ of the respondents are between 20 and 30 years while $50.8 \%$ are in the age group between $31-40$. A total of $9.1 \%$ are older than 40 and younger than 50 . Those who are above 50 years accounted for $2.3 \%$. The respondents are holders of bachelor's degrees (77\%) while $5.8 \%$ are holders of master's degrees and $1.9 \%$ are holders of Ph.D. degrees. They have access to the internet and CC with 58.9\% having experience of using the internet 
for more than six years and less than nine years. 37.2\% have experience of more than nine years. A total of 3.9\% have experienced between two to five years.

Table 1: Background of the Respondents

\begin{tabular}{|l|l|l|l|}
\hline Variable & Label & Frequency & Percentage \\
\hline \multirow{5}{*}{ Age } & $20-30$ years & 117 & 37.9 \\
\cline { 2 - 4 } & $31-40$ years & 157 & 50.8 \\
\cline { 2 - 4 } & $41-50$ years & 28 & 9.1 \\
\cline { 2 - 4 } & above 50 years & 7 & 2.3 \\
\hline \multirow{4}{*}{ Gender } & Male & 237 & 76.7 \\
\cline { 2 - 4 } & Female & 72 & 23.3 \\
\hline \multirow{5}{*}{ Education } & Diploma & 47 & 15.2 \\
\cline { 2 - 4 } & Bachelor & 238 & 77.0 \\
\cline { 2 - 4 } Internet & Master & 18 & 5.8 \\
\cline { 2 - 4 } & Ph.D. & 6 & 1.9 \\
\hline Access & Yes & 309 & 100.0 \\
\hline \multirow{2}{*}{\begin{tabular}{l} 
Length of using \\
\cline { 2 - 4 }
\end{tabular}} & 2-5 Years & 12 & 3.9 \\
\cline { 2 - 4 } & 6-9 years & 182 & 58.9 \\
\cline { 2 - 4 } & More than 9 years & 115 & 37.2 \\
\hline
\end{tabular}

\subsection{Measurement Model}

A measurement model was conducted to assess the model of this study. In this stage, the factor loading, as well as the indices, were checked. Factor loadings were greater than 0.60. Almost all the indices such as goodness of fit index (GFI) was 0.891, Tukerlewis index (TLI) was 0.952, Comparative fit index (CFI) was 0.946, and Chisq/df was 2.931, were achieved. The CFI is below the threshold of 0.90 . However, Hair et al. (2010) suggested researchers proceed with the analysis of three of the indices were achieved.

\subsubsection{Convergent Validity}

Convergent validity is achieved when the factor loading is greater than 0.60, Cronbach's Alpha greater than 0.70, composite reliability greater than 0.70, and Average Variance Extracted (AVE) is greater than 0.50 . Some of the items were deleted to improve the indices and achieve validity. Table 2 shows that all the thresholds were achieved. Thus, convergent validity was met.

Table 2: Convergent Validity of Sub-Variables

\begin{tabular}{|l|l|l|l|l|}
\hline Variables & $\begin{array}{l}\text { Factor loading } \\
\mathbf{> 0 . 6 0}\end{array}$ & $\begin{array}{l}\text { Cronbach's } \\
\text { Alpha>0.70 }\end{array}$ & Composite Reliability >0.70 & $\begin{array}{l}\text { Average Variance } \\
\text { Extracted >0.50 }\end{array}$ \\
\hline AT & $.909-.927$ & 0.946 & 0.936 & 0.831 \\
\hline PE & $.875-.921$ & 0.951 & 0.944 & 0.810 \\
\hline EE & $.901-.919$ & 0.949 & 0.945 & 0.812 \\
\hline SI & $.794-.857$ & 0.920 & 0.917 & 0.688 \\
\hline ITK & $.906-.939$ & 0.963 & 0.960 & 0.859 \\
\hline BI & $.828-.887$ & 0.931 & 0.920 & 0.742 \\
\hline Use Behavior & $.731-.937$ & 0.912 & 0.906 & 0.709 \\
\hline SA & $.807-.873$ & 0.911 & 0.905 & 0.705 \\
\hline
\end{tabular}

\subsubsection{Discriminant Validity}

The discriminant validity of the variables was achieved because the square root of AVE (bold and underlines) is greater than the cross-loading of the variables. Table 3 shows the discriminant validity.

Table 3: Discriminant Validity

\begin{tabular}{|l|l|l|l|l|l|l|l|}
\hline AT & PE & EE & SI & ITK & BI & $\begin{array}{l}\text { Use } \\
\text { behavior }\end{array}$ & $\begin{array}{l}\text { SA } \\
\text { 0.911 }\end{array}$ \\
\hline 0.410 & $\underline{\mathbf{0 . 9 0 0}}$ & & & & & & \\
\hline
\end{tabular}


"The Adoption of Cloud Computing Among Private Banks Employees in Libya"

\begin{tabular}{|l|l|l|l|l|l|l|l|}
\hline 0.559 & 0.670 & $\underline{\mathbf{0 . 9 0 1}}$ & & & & & \\
\hline 0.550 & 0.730 & 0.703 & $\underline{\mathbf{0 . 8 3 0}}$ & & & & \\
\hline 0.540 & 0.458 & 0.496 & 0.521 & $\underline{\mathbf{0 . 9 2 7}}$ & & & \\
\hline 0.187 & 0.203 & 0.190 & 0.235 & 0.335 & $\underline{\mathbf{0 . 8 6 2}}$ & & \\
\hline 0.096 & 0.066 & 0.092 & 0.166 & 0.184 & 0.465 & $\underline{\mathbf{0 . 8 4 2}}$ & \\
\hline 0.075 & 0.038 & 0.036 & 0.151 & 0.197 & 0.522 & 0.401 & $\underline{\mathbf{0 . 8 4 0}}$ \\
\hline
\end{tabular}

\subsection{Hypotheses Testing}

The structural model was conducted to test the hypotheses. All the indices were achieved except GFI.

\subsubsection{Direct Effect}

The hypotheses testing of the direct effect of individual factors is presented in Table 4. The table shows the hypotheses number $(\mathrm{H})$, dependent variable (DV), independent variable (IV), standard error (S.E), critical ratio (C.R), and p-value (P).

Table 4: Result of Hypotheses Testing of Individual Factors

\begin{tabular}{|l|l|l|l|l|l|l|l|l|}
\hline H & DV & & IV & Estimate & S.E. & C.R. & P & Label \\
\hline H1 & BI & $<---$ & Individual Factors & .363 & .105 & 3.455 & .001 & Supported \\
\hline H2 & BI & $<---$ & PE & .246 & .055 & 4.459 & .001 & Supported \\
\hline H3 & BI & $<---$ & EE & .191 & .052 & 3.647 & .001 & Supported \\
\hline H4 & BI & $<---$ & SI & .015 & .064 & .234 & .116 & Rejected \\
\hline H5 & BI & $<---$ & ITK & .147 & .056 & 2.597 & .009 & Supported \\
\hline H6 & BI & $<---$ & AT & .130 & .057 & 2.292 & .022 & Supported \\
\hline H7 & CC adoption & $<---$ & BI & .291 & .081 & 3.521 & 0.01 & Supported \\
\hline $\mathrm{R}^{2}$ & .592 & & & & & & & \\
\hline
\end{tabular}

According to the table, Libyan banks' BI toward CC is significantly affected by specific characteristics. As a result, hypothesis $\mathrm{H} 1$ is accepted. It's clear from Table 4 that PE has a big impact. As a result, $\mathrm{H} 2$ can be used. As can be observed in $\mathrm{H} 3,5,6,7$, other variables like EE, ITK, and AT have a considerable impact. There is a considerable impact of BI on the adoption of CC. Table 4 shows that SI has no significant impact on the BI (Estimate $=0.015, \mathrm{P}>0.05$ ). As a result, all save the SI hypothesis are supported (H4). An estimated 59\% of the variation in BI for CC adoption was explained by the model.

\subsubsection{Mediating Role of User Satisfaction}

The eighth hypothesis predicted that SA mediates the effect of individual factors on BI (H8). Table 5 presents the result of the mediation role of SA.

Table 5: Result of Mediation Role of SA

\begin{tabular}{|l|l|l|l|l|l|l|l|l|}
\hline H & D.V & & I.V & Estimate & S.E. & C.R. & P & Label \\
\hline & $\begin{array}{l}\text { Behavior } \\
\text { intention }\end{array}$ & $<---$ & SA & .180 & .059 & 3.049 & .002 & Supported \\
\hline \multirow{2}{*}{ H8 } & BI & $<---$ & Individual Factors & .290 & .102 & 2.84 & .001 & \\
\cline { 2 - 9 } & SA & $<---$ & Individual Factors & .160 & .072 & 2.22 & .007 & Supported \\
\hline
\end{tabular}

Table 5 shows that the direct effect of individual factors on BI reduced from .363 in Table 4 to .290 in Table 5 (after including the mediator). This indicates that the mediation occurred. In addition, the indirect effect through SA is significant. Since both; the direct effect and the indirect effect are significant, the mediation is partial and H8 is supported.

\section{DISCUSSION}

This investigation examined whether or not Libyan bank staff was using CC. The study indicated that the BI's acceptance of CC is influenced by several individual characteristics. The PE, followed by EE, ITK, and AT, is the most critical element. CC adoption is also influenced by the use of the BI. SI was found to be a non-significant predictor of the BI, according to the study. Results from this study are consistent with findings from previous research. Individual variables have been demonstrated to be an important predictor of CC adoption in previous research (Lian, 2015). The adoption of CC technology is heavily influenced by PE and EE (Bellaaj et al., 2015; Lian, 2015; Cao et al., 2013). The acceptance of CC is influenced by BI (Arpaci et al., 2015). A partial mediating impact of the SA indicates that SA can explain some of the association between individual variables and BI. There is some evidence to suggest that the slow diffusion of new ideas may account for the small impact of SI, as noted by Venkatesh et al (2003). 


\section{"The Adoption of Cloud Computing Among Private Banks Employees in Libya"}

Investigating the individual factors provides the decision-makers with information regarding the factors that concern the employees who are going to use the CC system. The PE, EE, AT and ITK are the most critical factor that decision-makers have to focus on when developing and adopting the CC system.

\section{IMPLICATIONS}

This study investigated the adoption of CC among employees at private banks in Libya. Studies about CC in developing countries are limited and this study has contributed in this regard. The study investigated the CC adoption factors using the UTAUT model. The study has enriched the literature and filled the gaps related to the use of UTAUT in CC. In addition, the study enriched the literature with an academic article that tackles the issue of $\mathrm{CC}$ adoption by banks.

The findings of this study are generalizable on all the Libyan private banks and it can be carefully generalized to other countries providing that the culture, ITK, and CC adoption factors are similar in these countries. In other words, the finding might be generalized to developing countries, but it would be difficult to generalize the finding to developed countries due to the differences in technology usage and level of ITK and IT infrastructure in these countries.

\section{CONCLUSION}

There are some limitations in this study that can be used as avenues for future works. This study was conducted on Libyan private banks. Thus, findings might not be generalized on the public banks, which follow different procedures and requires a high routine in decision making. Hence, future researchers are recommended to investigate the adoption of CC by public banks. In addition, the study was conducted on employees, customers were not involved in this study. Thus, to include the customers, future researchers have to add factors related to the customer's adoption and usage of the banking CC system. The study tested hypotheses related to individual factors. Future studies can add other factors such as organizational and technological factors.

\section{REFERENCES}

1. Al-Masri, O.H. and Ahmad, M.S. (2017), "A Conceptual Framework for a Problem Resolution Support System (PReSS)", Journal of Advances in Information Technology, No. January, pp. 148-153.

2. Alaaraj, S., Mohamed, Z.A. and Bustamam, U.S.A. (2017), "Do Knowledge Management Capabilities Reduce the Negative effect of Environment Uncertainties on Organizational Performance? A Study of Public Listed Companies in Malaysia", International Journal of Economic Research, Vol. 14 No. 15, pp. 443-456.

3. Alaaraj, S., Mohamed, Z.A. and Bustamam, U.S.B.A. (2018), "External Growth Strategies and Organizational Performance in Emerging Markets: The Mediating Role of Inter-Organizational Trust", Review of International Business and Strategy, Vol. 28 No. 2.

4. Alaaraj, S., Zainal, A.M. and Bustamam, U. (2015), "The Effect of Knowledge Management Capabilities on the Performance of Malaysian Large-Scale Organizations: An Empirical Study", Advances in Global Business Research, Vol. 12 No. 1, pp. 1024-1038.

5. Alaarj, S., Mohamed, Z.A. and Bustamam, U.S.A. (2017), "The Effect of Knowledge Management Capabilities on Performance of Companies : A Study of Service Sector”, International Journal of Economic Research, Vol. 14 No. 15, pp. 457-470.

6. Alaarj, S., Zainal, A.M. and Bustamam, U. (2016), "Mediating Role of Trust on the Effects of Knowledge Management Capabilities on Organizational Performance", Procedia - Social and Behavioral Sciences, Vol. 235 No. 2016, pp. 729 738.

7. Albakri, S.H., Shanmugam, B., Samy, G.N., Idris, N.B. and Ahmed, A. (2014), "Security risk assessment framework for cloud computing environments", Security and Communication Networks, Vol. 7 No. 11, pp. 2114-2124.

8. Apostu, A., Rednic, E. and Puican, F. (2012), "Modeling Cloud Architecture in Banking Systems", Procedia Economics and Finance, Vol. 3, pp. 543-548.

9. Arpaci, I. (2016), "Understanding and predicting students' intention to use mobile cloud storage services", Computers in Human Behavior, Elsevier Ltd, Vol. 58, pp. 150-157.

10. Arpaci, I., Kilicer, K. and Bardakci, S. (2015), "Effects of security and privacy concerns on educational use of cloud services", Computers in Human Behavior, Elsevier Ltd, Vol. 45, pp. 93-98.

11. Asadi, S., Nilashi, M., Husin, A.R.C. and Yadegaridehkordi, E. (2016), "Customers perspectives on adoption of cloud computing in banking sector", Information Technology and Management, Springer US, pp. 1-26.

12. Bellaaj, M., Zekri, I. and Albugami, M. (2015), "The continued use of e-learning system: An empirical investigation using UTAUT model at the University of Tabuk", Journal of Theoretical and Applied Information Technology, Vol. 72 No. 3, pp. $464-474$.

13. Boulton, C. (2016), "Why banks are finally cashing in on the public cloud", $C I O$, p. 3.

14. Burda, D. and Teuteberg, F. (2014), "The role of trust and risk perceptions in cloud archiving - Results from an empirical 


\section{"The Adoption of Cloud Computing Among Private Banks Employees in Libya"}

study”, Journal of High Technology Management Research, Elsevier Inc., Vol. 25 No. 2, pp. 172-187.

15. Cao, Y., Bi, X. and Wang, L. (2013), "A Study on User Adoption of Cloud Storage Service in China: A Revised Unified theory of Acceptance and Use of Technology Model", 2013 International Conference on Information Science and Cloud Computing Companion, No. 2012, pp. 287-293.

16. Capgemini. (2011), "Cloud Computing in Banking”, Capgemini, p. 12.

17. Chiu, R.K. and Francesco, A.M. (2003), "Dispositional traits and turnover intention: Examining the mediating role of job satisfaction and affective commitment", International Journal of Manpower, Vol. 24, pp. 284-298.

18. Davis, F.D. (1989), "Perceived Usefulness, Perceived Ease of Use, and User Acceptance of Information Technology", Source: MIS Quarterly, Vol. 13 No. 3, pp. 319-340.

19. Dehkordi, L., Rasouli, R. and Zebardast, Z. (2011), "Development of e-government services in iran: a comparison of adoption constructs", Interdisciplinary Journal of Research ..., Vol. 1 No. February, pp. 30-37.

20. DeLone, W.H. and McLean, E.R. (2003), "The DeLone and McLean Model of Information Systems Success : A Ten-Year Update”, Journal of Management Information Systems, Vol. 19 No. 4, pp. 9-30.

21. El-Gazzar, R.F. (2014), "A Literature Review on Cloud Computing Adoption Issues in Enterprises", Creating Value for All Through IT (IFIP Advances in Information and Communication Technology), Vol. 429, pp. 214-242.

22. Eljayash, K. (2015), "Documentation of Environmental Disclosure Practices in the Oil Companies in the Countries of the Arab Spring - Some Evidences from Egypt, Libya and Tunisia", Journal of Economics, Business and Management, Vol. 3 No. 10, available at:https://doi.org/10.7763/JOEBM.2015.V3.315.

23. Elkaseh, A.M., Wong, K.W. and Fung, C.C. (2015), "The Acceptance of E-learning as a Tool for Teaching and Learning in Libyan Higher Education", International Journal of Information Technology, Vol. 3 No. 4, pp. 1-11.

24. Elzamly, A., Hussin, B., Naser, S.A., Khanfar, K., Doheir, M., Selamat, A. and Rashed, A. (2016), "A new conceptual framework modelling for cloud computing risk management in banking organizations", International Journal of Grid and Distributed Computing, Vol. 9 No. 9, pp. 137-154.

25. Guner, E. and Sneiders, E. (2014), "Cloud Computing Adoption Factors in Turkish", Journal of Enterprise Information Management, Vol. 26 No. 3, pp. 250-275.

26. Hair, J. F., Anderson, R. E., Babin, B. J., Black, W.C. (2010), Multivariate Data Analysis: A Global Perspective, Upper Saddle River, 7th ed., Pearson, NJ, available at:https://doi.org/10.1016/j.ijpharm.2011.02.019.

27. IBM. (2013), "Cloud computing for banking", IBM Cloud Computing for Banking, Vol. 1, pp. 1-16.

28. IBM. (2016), "Transform the digital customer experience with financial services in the cloud", IBM Cloud Computing for Banking.

29. Lian, J.W. (2015), "Critical factors for cloud based e-invoice service adoption in Taiwan: An empirical study", International Journal of Information Management, Elsevier Ltd, Vol. 35 No. 1, pp. 98-109.

30. Lian, J.W., Yen, D.C. and Wang, Y.T. (2014), "An exploratory study to understand the critical factors affecting the decision to adopt cloud computing in Taiwan hospital", International Journal of Information Management, Elsevier Ltd, Vol. 34 No. 1, pp. 28-36.

31. Low, C., Chen, Y. and Wu, M. (2011), "Understanding the determinants of cloud computing adoption", Industrial Management \& Data Systems, Vol. 111 No. 7, pp. 1006-1023.

32. Lowry, P.B. and Gaskin, J. (2014), "Partial least squares (PLS) structural equation modeling (SEM) for building and testing behavioral causal theory: When to choose it and how to use it", IEEE Transactions on Professional Communication, Vol. 57 No. 2, pp. 123-146.

33. Mckinsey. (2016), "Banking on the cloud", McKinsey, New York, April, p. 3.

34. Mell, P. and Grance, T. (2011), "The NIST Definition of Cloud Computing Recommendations of the National Institute of Standards and Technology", Nist Special Publication, Vol. 145, p. 7.

35. Mohamed, A.E.A. (2013), "Improving the libyan customers' trust and acceptance for online banking technology", $P Q D T$ - UK \& Ireland, No. June, p. 1.

36. Park, E. and Kim, K.J. (2014), “An integrated adoption model of mobile cloud services: Exploration of key determinants and extension of technology acceptance model", Telematics and Informatics, Elsevier Ltd, Vol. 31 No. 3, pp. 376-385.

37. Park, S.C. and Ryoo, S.Y. (2013), "An empirical investigation of end-users' switching toward cloud computing: A two factor theory perspective", Computers in Human Behavior, Elsevier Ltd, Vol. 29 No. 1, pp. 160-170.

38. Patani, S., Kadam, S. and Jain, P. V. (2014), "Cloud Computing in the Banking sector : A survey", International Journal of Advanced Research in Computer and Communication Engineering, Vol. 3 No. 2, pp. 5640-5643.

39. Picoto, W., Grespo, N. and Kahn, F. (2014), "Cloud Computing Usage and Organizational Mobility - an Empirical Assessment", ISEG School of Economics and Management Of, Vol. 20 No. 1, pp. 1-14.

40. Pilevari, N., Toloei, A. and Sanaei, M. (2013), "A model for evaluating cloud-computing users' satisfaction", African Journal of Business Management, Vol. 7 No. 16, pp. 1405-1413. 
41. Rezvani, A., Chang, A., Wiewiora, A., Ashkanasy, N.M., Jordan, P.J. and Zolin, R. (2016), "Manager emotional intelligence and project success: The mediating role of job satisfaction and trust", International Journal of Project Management, Elsevier Ltd and Association for Project Management and the International Project Management Association, Vol. 34 No. 7, pp. 1112-1122.

42. Shawish, A. and Salama, M. (2014), "Cloud computing: Paradigms and technologies", Studies in Computational Intelligence.

43. Spagnoli, P. and Caetano, A. (2012), "Personality and organisational commitment: The mediating role of job satisfaction during socialisation", Career Development International, Vol. 17 No. 3, pp. 255-275.

44. Venkatesh, V., Morris, M., Davis, G. and Davis, F. (2003), "User Acceptance of Information Technology: Toward a Unified View", MIS Quarterly, Vol. 27 No. 3, pp. 425-478.

45. Wixom, B.H. and Todd, P.A. (2005), “A Theoretical Integration of User Satisfaction and Technology Acceptance”, Vol. 16 No. 1, pp. 85-102.

46. Wu, W.-W. (2011a), "Mining significant factors affecting the adoption of SaaS using the rough set approach", Journal of Systems and Software, Elsevier Inc., Vol. 84 No. 3, pp. 435-441.

47. Wu, W.W. (2011b), "Developing an explorative model for SaaS adoption", Expert Systems with Applications, Elsevier Ltd, Vol. 38 No. 12, pp. 15057-15064.

48. Zhang, W. and Chen, Q. (2010), "From E-government to C-government via cloud computing", Proceedings of the International Conference on E-Business and E-Government, ICEE 2010, pp. 679-682. 